\title{
PENGEMBANGAN KOMUNIKASI MULTIKANAL UNTUK MONITORING INFRASTRUKTUR JARINGAN BERBASIS BOT TELEGRAM
}

\author{
Rio Juniyantara Putra ${ }^{1}$, Nyoman Putra Sastra ${ }^{2}$, Dewa Made Wiharta ${ }^{3}$ \\ Jurusan Teknik Elektro, Fakultas Teknik Universitas Udayana \\ Email: ryojuniyantara@gmail.com ${ }^{1}$, putra.sastra@unud.ad.id ${ }^{2}$, wiharta@unud.ac.id ${ }^{\underline{3}}$
}

\begin{abstract}
Abstrak
Penelitian ini mengusulkan suatu solusi untuk mengoptimalkan sistem monitor infrastruktur jaringan di Universitas Udayana. Optimasi sistem monitor dimulai dari pencarian segala informasi tentang perangkat jaringan internet pada server OpenNMS dan Router Mikrotik. Layanan ini dilakukan dengan menggunakan aplikasi Telegram. Pengguna dapat melakukan komunikasi dengan Bot Telegram yang sudah di integrasikan dengan sistem monitoring agar dapat memberikan informasi tentang jaringan internet di Universitas Udayana. Aplikasi Telegram dipilih karena aplikasi ini gratis, ringan, dan multiplatform serta didukung dengan Bot API yang sangat lengkap dan terus berkembang. Segala bentuk respon sudah dirancang dinamis dengan memanfaatkan sumber daya yang ada, dan sudah dibuat dalam penelitian ini sebagai prototype dengan beberapa perintah.
\end{abstract}

Kata Kunci : Bot, Sistem Monitoring, Telegram,

\section{PENDAHULUAN}

Monitoring infrasturktur jaringan merupakan suatu hal yang sangat penting untuk menjaga kelangsungan Service Level Agrement (SLA) [1] dari sebuah layanan. Agar mudah, dan efektif dan efisien, maka berbagai model telah ditawarkan oleh berbagai pengembang aplikasi/layanan. dapat tetap terjaga oleh sebuah sistem yang digunakan untuk memantau kondisi perangkat jaringan baik itu server, router, maupun perangkat jaringan lainnya yang terhubung ke jaringan. Sistem monitoring ini ditargetkan agar sistem dapat mengakses resource dan service yang ditangani perangkat jaringan, dapat memberikan informasi kepada network administrator bila terjadi masalah dalam jaringan.

Dalam memantau sebuah jaringan komputer dibutuhkan seorang network administrator yang bertanggung jawab atas pengelolaan jaringan internet. Salah satu tanggung jawabnya yaitu memantau jaringan komputer agar tetap berada pada keadaan optimal. Dalam memonitoring suatu jaringan komputer diperlukan ketelitian, agar informasi yang didapatkan dari hasil monitoring sesuai dengan kondisi sebenarnya.

Sistem monitoring infrastruktur jaringan pada Universitas Udayana saat ini masih menggunakan sistem monitoring berbasis web, OpenNMS itu sendiri merupakan merupkan aplikasi manajemen jaringan berbasis free/open source[2], dan terintegrasi dengan banyak perangkat jaringan. Network administrator sangat sering menerima keluhan dari pengguna karena jaringan yang bermasalah, dan setiap terjadi permasalahan mengharuskan network administrator membuka aplikasi web monitoring untuk mencari informasi terkait permasalahan yang terjadi dan mengharuskan menggunakan jaringan intranet.

Melihat permasalahan ini, maka dalam penelitian ini ditawarkan sebuah solusi untuk pemberian alert dan pesan menggunakan layanan Telegram Bot, yang akan memberikan custom tool dan social service untuk network administrator yang diintegrasikan dengan sistem monitoring infrastruktur jaringan di Universitas Udayana. Layanan yang disediakan berupa pencarian 
informasi infrastruktur jaringan seperti server, router, dan switch.

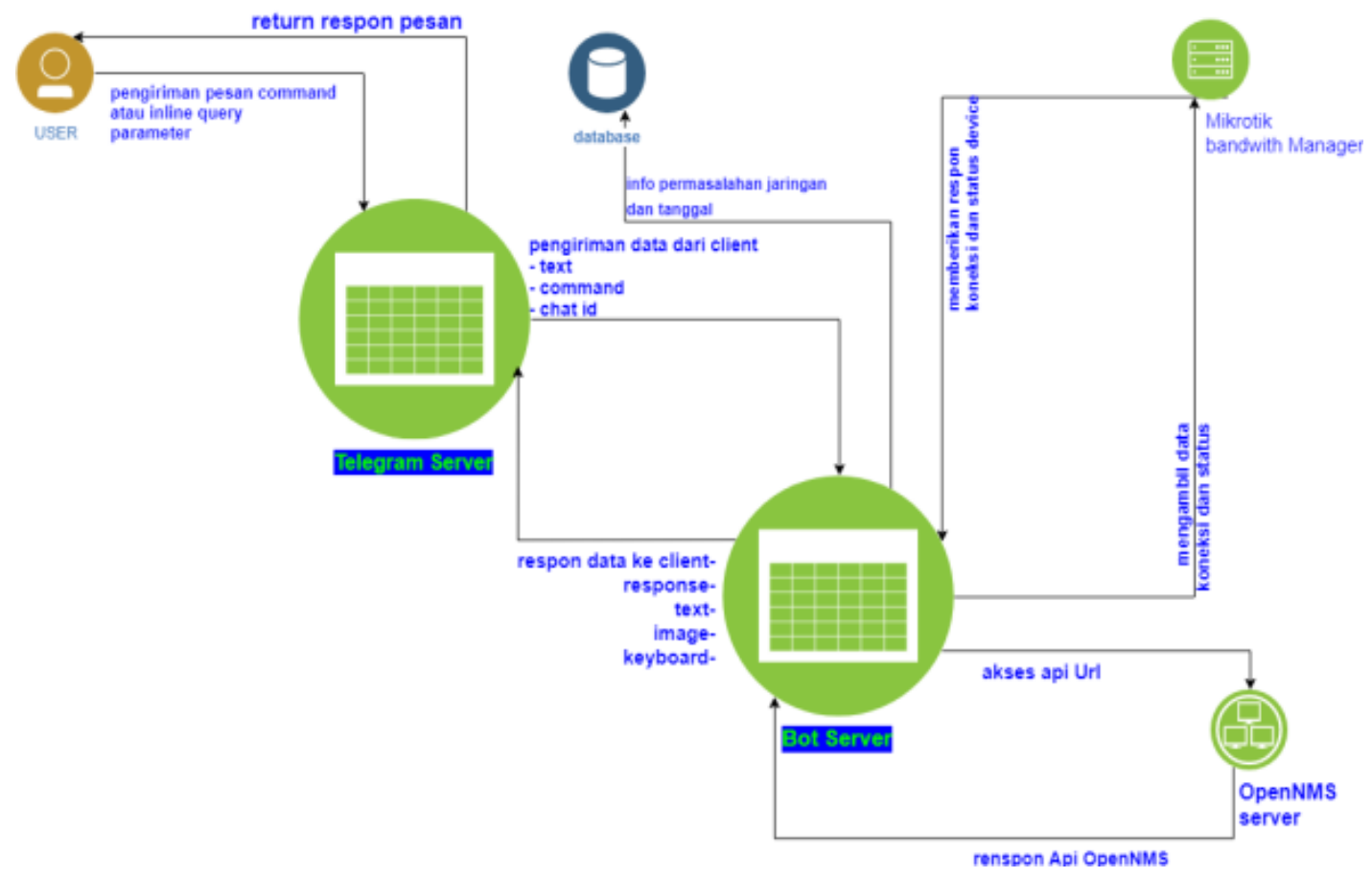

Gambar 1 Arsitektur Sistem

Layanan ini akan dilakukan dengan aplikasi messanger Telegram. Network administrator akan berkomunikasi dengan Bot Telegram yang dirancang sesuai dengan kebutuhan agar memberikan informasi perangkat dan permasalahan lainnya.

Telegram Bot merupakan aplikasi pihak ketiga yang berjalan didalam sistem Telegram [3], dan merupakan salah satu dari layanan yang disediakan oleh aplikasi Telegram. Telegram dipilih karena aplikasi ringan, gratis, multiplatform, dan juga memiliki BOT API yang lengkap dan terus berkembang, sehingga memungkinkan untuk membuat Bot yang dinamis, pintar dan dapat merespon pesan dari network administrator. Bot dirancang memberikan respon yang dinamis dengan memanfaatkan sumber daya dari infrastruktur jaringan Universitas Udayana. Tentunya diharapkan mampu memberikan kemudahan bagi network administrator untuk mengakses informasi tentang infrastruktur jaringan maupun permasalahan yang terjadi dengan mudah.

\section{DESAIN SISTEM}

Penelitian ini memanfaatkan fitur Bot dari Telegram yang nantinya digunakan untuk merespon pesan dari network administrator. Arsitektur dari Telegram Bot dapat dilihat pada Gambar 1. Network administrator mengirim pesan dari perangkat yang digunakan ke akun Telegram Bot. Pesan akan diterima oleh Telegram server dan dilanjutkan ke Bot server. Bot server akan memproses pesan tersebut untuk dapat merespon request yang dikirimkan oleh network administrator berupa command atau inline query. Respon akan dikirimkan kembali ke client melalui Telegram server. Setiap teks yang dikirimkan akan bertindak sebagai command/perintah yang berpengaruh terhadap bentuk respon ke client.

Untuk menjalankan layanan yang disediakan bot, pengguna harus mengirimkan beberapa perintah yang sudah disediakan. Contoh beberapa perintah sebagai beri 
1. Istart - perintah pertama yang akan dikirimkan pengguna jika pertama kali menggunakan layanan bot.

2. Jopennms - perintah untuk menampilkan menu dari layanan OpenNMS.

3. /mikrotik - perintah ini digunakan untuk menampilkan menu dari layanan mikrotik.

4. ./reset - perintah ini digunakan untuk mereset tombol dari tombol menu.

\subsection{Squence Diagram Akses Data API OpenNMS}

Pada bagian ini jenis layanan yang disediakan oleh Bot server adalah pengaksesan API OpenNMS dengan menjalankan perintah command atau inline query, dan selanjutnya akan mengambil informasi dari respon API tersebut. Setelah itu data akan dilempar ke aplikasi Telegram client dalam kasus ini yang berperan sebagai network administrator. Rancangan sequence diagram akses API server ditunjukkan pada Gambar 2.

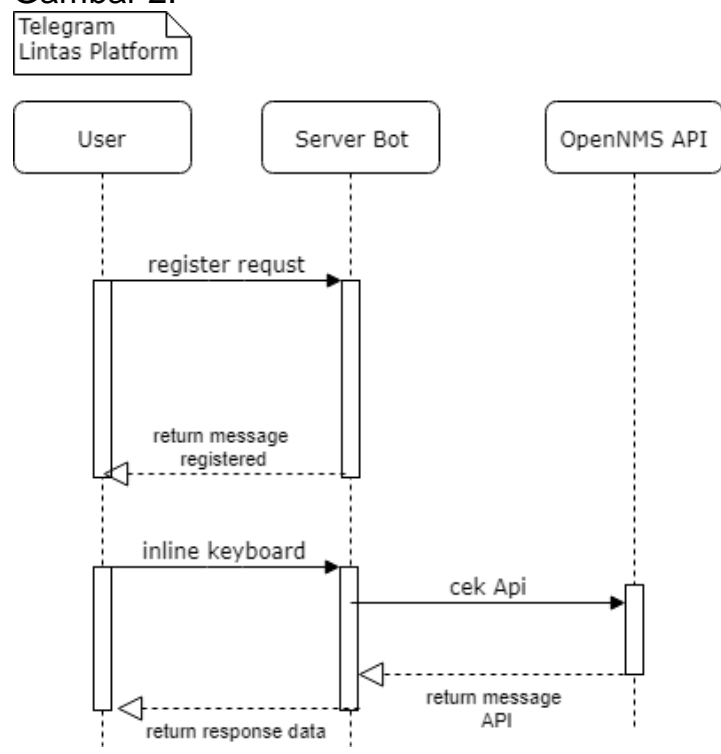

Gambar 2 Sequence Akses Data API OpenNMS

\subsection{Squence Diagram Akses API Router Mikrotik}

Pada bagian ini jenis layanan yang disediakan oleh Bot server adalah mengakses api mikrotik untuk mengambil informasi tentang informasi sistem pada router Mikrotik dan status koneksi dengan menjalankan perintah command atau inline query, dan menyimpan informasi tersebut ke dalam database. Selanjutnya client/network administrator akan mendapatkan informasi dari respon API tersebut melalui client Telegram yang dimiliki. Rancangan sequence diagram akses data api mikrotik ditunjukkan pada Gambar 3.

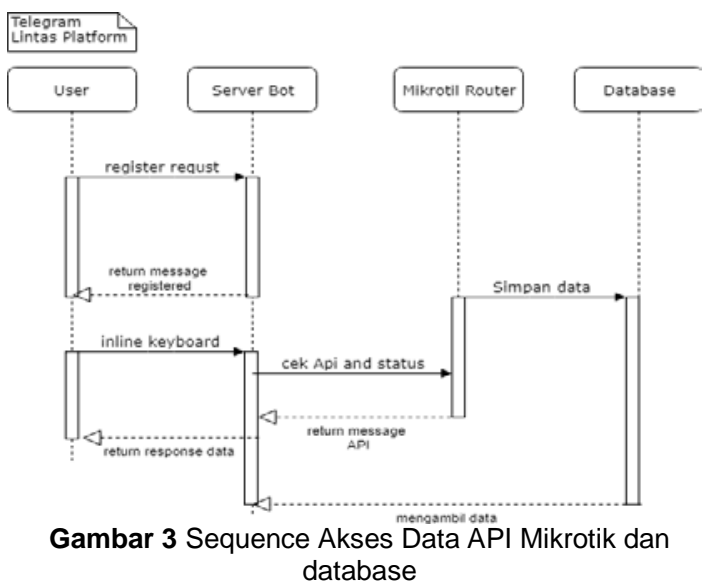

\subsection{Referensi}

\subsubsection{NMS}

Network Monitoring System adalah sistem ekstra atau kumpulan dari beberapa sistem yang memiliki tugas untuk mengamati atau memonitor sistem-sistem jika kemungkinan terjadinya masalah-masalah pada sistem tersebut agar dapat dideteksi secara dini.[4]

\subsubsection{DBMS}

DBMS adalah Kumpulan file yang saling berkaitan satu dengan yang lainnya bersama dengan program untuk pengelolaannya. Satu Database Management System (DBMS) memiliki satu koleksi data yang saling berelasi dan satu program untuk mengakses data dari kolesi data tersebut. DBMS terdiri dari beberapa database dan set program pengelola untuk melakukan kegiatan seperti menambah data, menghapus data, mengambil dan membaca data.[5]

\subsubsection{Node JS}

Node.js adalah sistem perangkat lunak yang didesain untuk keperluan pengembangan aplikasi web. Aplikasi ini ditulis dalam bahasa JavaScript maupun Typescript, menggunakan basis event dan asynchrounous I/O. Tidak seperti kebanyakan bahasa JavaScript yang dijalankan pada 
peramban, Node.js merupakan bahasa pemrogramamn server side yang dieksekusi sebagai aplikasi server. Aplikasi ini dibangun dari V8 JavaScript Engine buatan Google dan beberapa modul bawaan yang sudah terintegrasi.[6]

\subsubsection{RESTful API}

RESTful API merupakan salah satu jenis web service yang menerapkan konsep perpindahan antar state. State disini dapat digambarkan seperti jika browser dari user request suatu halaman web, maka server akan mengirimkan state halaman web yang sekarang ke browser. Bernavigasi melalui link endpoint yang disediakan sama halnya dengan mengganti state dari halaman web. Begitu pula REST bekerja, dengan bernavigasi melalui link-link HTTP untuk melakukan aktivitas yang sesuai, seolah-olah terjadi perpindahan state satu sama lain.[7]

\section{HASIL DAN PEMBAHASAN}

\subsection{Hasil Pengujian}

Pengujian Telegram Bot pada penelitian ini dilakukan dengan menggunakan metode black box dengan mencoba semua perintah yang sudah diatur dalam Bot dengan menyesuaikan dengan fungsinya masingmasing. Beberapa contoh screenshot pengujian Telegram Bot dapat dilihat pada Gambar 9.

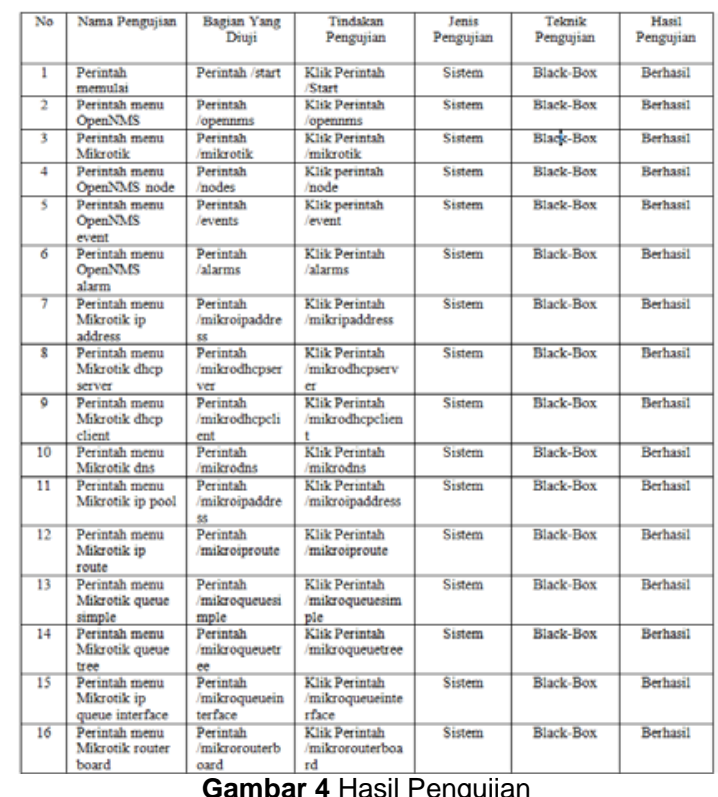

\subsection{Pembahasan dan Gambaran Umum Sistem Keseluruhan}

Aplikasi Bot dibangun dengan menggunakan bahasa pemrograman Jaravasript pada platform Node JS. Komunikasi dari server ke Bot server menggunakan metode long polling. Beberapa contoh screenshot penggunaan Bot oleh network administrator dapat dilihat pada Gambar 5 sampai dengan Gambar 9.
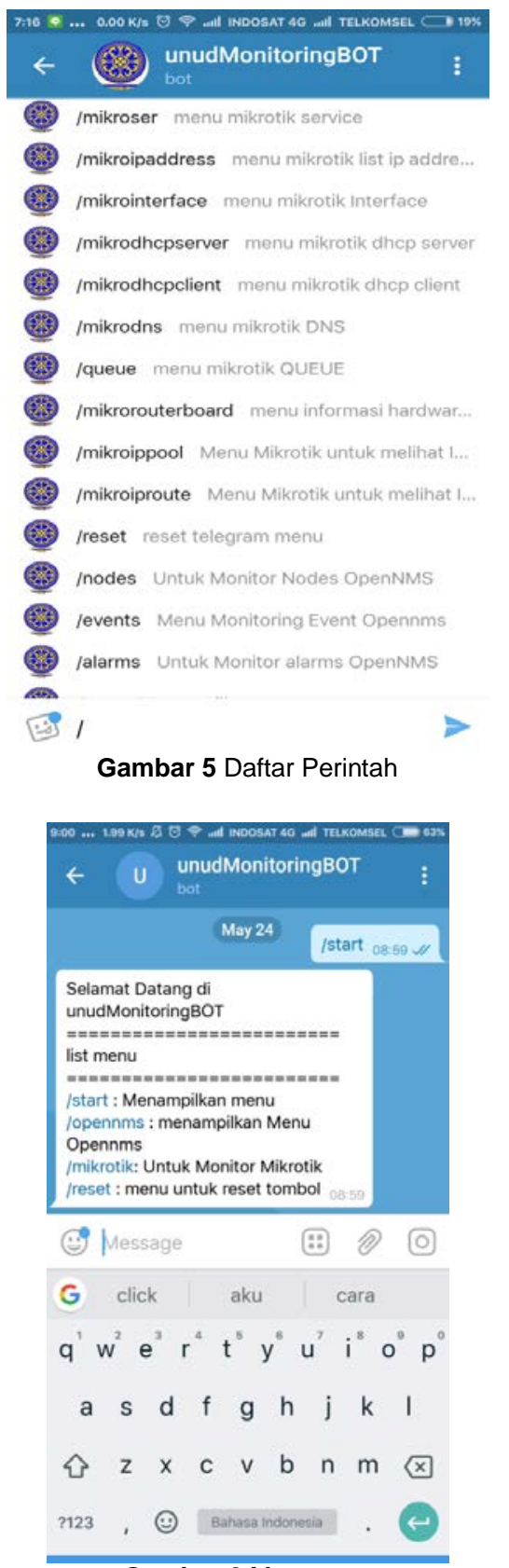

Gambar 6 Menu start 


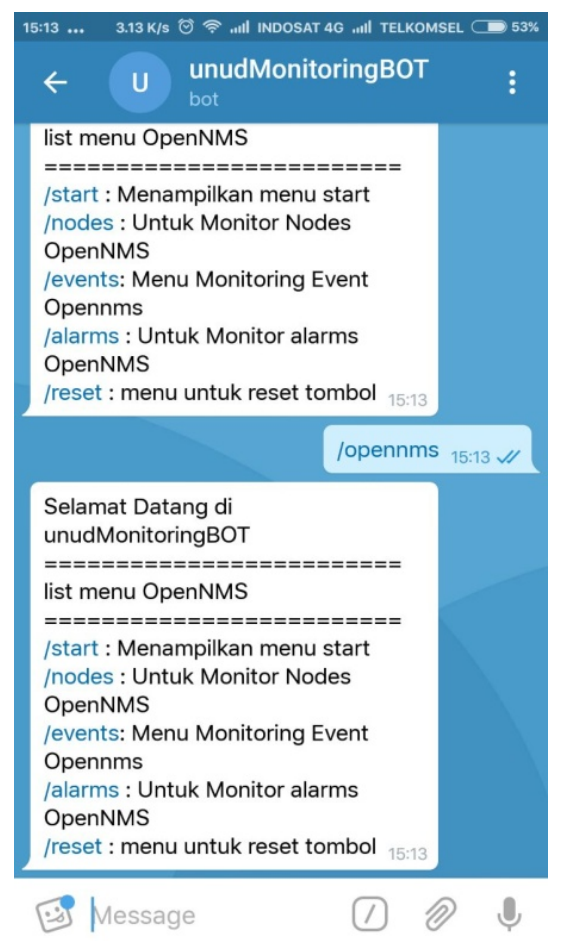

Gambar 7 Menu OpenNMS

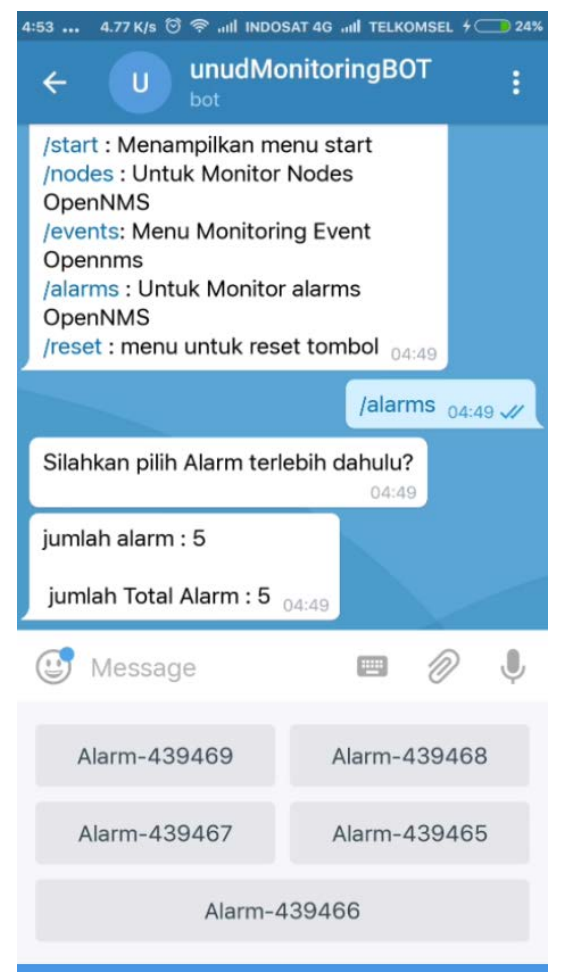

Gambar 8 Daftar Alarm OpenNMS

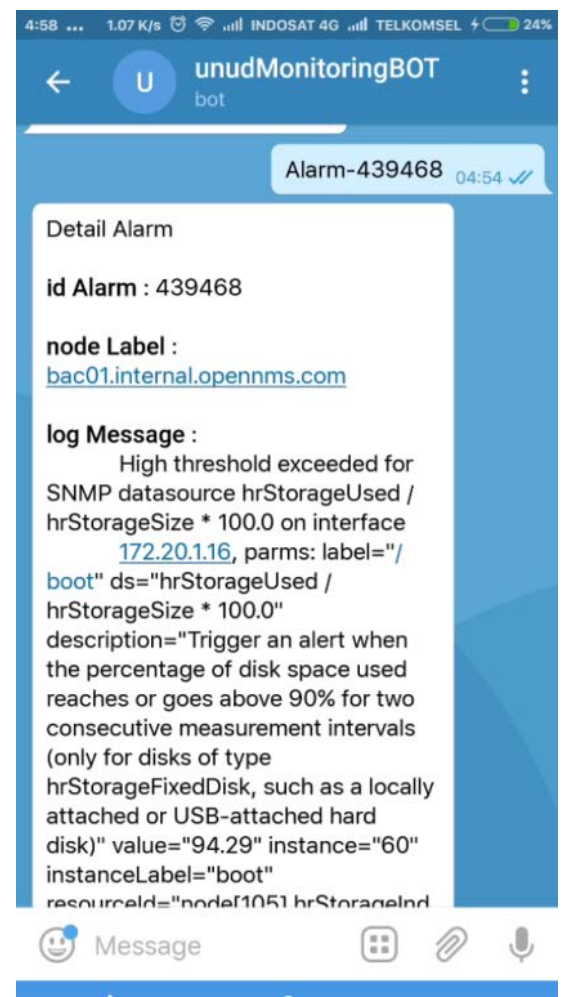

Gambar 9 Detail Alarm OpenNMS

\section{SIMPULAN}

\subsection{SIMPULAN}

Simpulan yang dapat diambil berdasarkan hasil dari pengujian dan pembahasan yang telah dilakukan adalah sebagai berikut:

Aplikasi ini dirancang dengan menggunakan Bot Telegram dan diintegrasikan dengan server OpenNMS dan Router Mikrotik, sehingga pengguna dapat memonitoring server maupun perangkat jaringan lainnya dengan mudah. Bot Telegram untuk layanan monitoring telah berhasil dibuat, terdapat beberapa command yang dibuat dalam penelitian ini sebagai prototype awal. Output yang diberikan oleh Bot berupa teks dan tombol. Tidak menutup kemungkinan untuk dapat memberikan output berupa dokumen, gambar, audio, video dan format lainnya.

Untuk mengintegrasikan API OpenNMS dan Router Mikrotik dengan backend system Telegram yaitu dengan merancang sistem yang bisa mengakses informasi data OpenNMS dan Router Mikrotik dan 
mengintegrasikan sistem tersebut dengan Bot Telegram.

\subsection{SARAN}

Aplikasi monitoring ini dapat dikembangkan agar dapat dijalankan di media sosial lainnya seperti Line Bot, Messenger Bot, dan lain - lainnya.

Pengujian pada penelitian ini terbatas hanya dengan beberapa pengguna. Diharapkan untuk pengujian lebih lanjut bisa menggunakan pengguna yang lebih banyak.

Aplikasi monitoring terbatas hanya diintegrasikan dengan OpenNMS dan Router Mikrotik, diharapkan untuk kedepannya dapat diintegrasikan dengan sistem monitoring lainnya seperti cacti, zabbix dan lainnya.

\section{DAFTAR PUSTAKA}

[1] Waspada I, Analisa Best Practice Service Level Management (SLM) CISCO Menggunakan Kriteria Kelengkapan Dari Thomas SCHAAF, Jurnal Masyarakat Informatika, 2010;2:1.

[2] Rusmana $M U$, Pengembangan Aplikasi Sistem Monitoring Jaringan Menggunakan OpenNMS Berbasis Smartphone Android, Jurnal IImiah Komputer dan Informatika, 2016;1:2.

[3] https://core.telegram.org/bots, diakses tanggal 15 Agustus 2018.

[4] Amnur H,Deddy, Perancangan dan Implementasi Network Monitoring Sistem Menggunakan Nagios dengan Email dan SMS Alert, Poli Rekayasa, 2014;10:1.

[5] Kristanto $\mathrm{H}$, Konsep dan Perancangan Database, II, Yogyakarta, ANDI, 2009

[6] Iqbal M, Implementasi Klien SIP Berbasis Web Menggunakan HTML5 dan Node.js, Jurnal Teknik ITS, 2012;1:A-243.

[7] Rismayani, Sistem Manajemen Administrasi Kependudukan Tingkat Pedesaan Berbasis RESTful API di Kabupaten Bone, Jurnal Pekommas, 2017;2:9. 